\title{
Assessment of the Effectiveness of Complex Use of Biofungicides on Spring Wheat
}

\author{
Radik Safin* and Guzel Khusainova \\ Kazan State Agrarian University, Kazan, 420011, Russia
}

\begin{abstract}
In 2018-2019, the studies were carried out in order to assess the effectiveness of the use of various biofungicides on spring bread wheat (Triticum aestivum L.) on grey wood soil in the Predkamsk zone of the Republic of Tatarstan. The agents based on Bacillus subtilis strain 63-Z (Baxis $®$ ) and Pseudomonas aureofaciens strain (Pseudobacterin $2{ }^{\circledR}$ ) were used as biofungicides. The chemical fungicides were used as a standard (for seed treatment - prothioconazole + tebuconazole (Lamador ${ }^{\circledR}$ ); for spraying spiroxamine + tebuconazole + triadimenol $\left(\right.$ Falcon $\left.\left.{ }^{\circledR}\right)\right)$. The research results showed that the use of biofungicides for seed treatment and spraying during the earing phase of wheat has a pronounced effect on the length of the stem and the number of grains in the ear. Under the influence of the use of biofungicides, the damage to plants by root rot, leaf septoria and powdery mildew was reduced. In terms of their effect on leaf septoria and powdery mildew, the chemical fungicides were somewhat superior to biological ones. The highest yield of spring soft wheat was obtained using the scheme in which the seeds were treated with Baxis and the plants in the earing phase were sprayed with Pseudobacterin 2. This scheme provided the increase in yield by $1.1 \mathrm{t} /$ ha compared to control and by $0.29 \mathrm{t} /$ ha when using standard chemical fungicides for seed treatment and spraying of crops. The use of such a scheme significantly reduces the cost of the protection of wheat plants from diseases. As a result of research, it was shown that with a weak and medium development of diseases, the use of biofungicides can be an effective alternative to the use of standard chemical fungicides.
\end{abstract}

\section{Introduction}

Wheat is one of the main crops in the world and plays an essential role in global food security [1-3]. In the Republic of Tatarstan, spring soft wheat (Triticum aestivum L.) is the main grain crop $[4,5]$. Various infectious diseases are one of the reasons for the decline in yield and quality of wheat grain [6-8]. Integrated pest management (IPM) $[9,10]$ for pathogens is widely used to control wheat diseases. The resistant varieties, reasonable crop rotations, optimal fertilization rates, compliance with the requirements for wheat cultivation technology are among the most important elements of such systems $[11,12]$.

The use of various fungicides belonging to different classes (groups) of chemical compounds [13, 14] occupies significant place in the protection of wheat from diseases. One of the significant problems associated with the use of fungicides is the development of resistance to them in phytopathogens $[15,16]$. The relatively high cost of these drugs also remains a significant problem.

In recent years, more and more attention is paid to the biological protection of plants from diseases taking into account the growing interest in the production of food with a minimum negative impact on the environment and in connection with the development of organic farming $[17,18]$.
The biological method of protecting plants from diseases is based on the use of various drugs based on different microorganisms or their metabolic products $[19,20]$. The use of biological agents in the control of plant diseases is based on different mechanisms of the effect of microbial biological control agents (MBCAs) on phytopathogens [21,22].

The main groups of microbiological control agents include bacteria of the genera Pseudomonas, Bacillus, and fungi of the genus Trichoderma [23, 24]. On the basis of these biological agents, a large number of different biofungicides are produced, which can be a definite alternative to traditional chemical fungicides, especially in the case of weak and medium development of diseases [25]. Significant advantages of biofungicides in comparison with chemical preparations are their relative safety for the environment and lower cost [26]. Biofungicides produced in Russia include Baxis ${ }^{\circledR}$ (Bacillus subtilis strain 63-Z) and Pseudobacterin 2® (Pseudomonas aureofaciens strain BS 1393).

Fungicides for the control of plant diseases can be used in various ways, but most often seed treatment and spraying are used for these purposes during the period of active growth and development of plants. In the systems of protection of spring wheat from diseases adopted in the Republic of Tatarstan, both seed treatment and a single treatment of plants with fungicides during the

\footnotetext{
* Corresponding author: radiksaf2@mail.ru
} 
earing phase are used. In this regard, there is a need for a comprehensive assessment of the effectiveness of disease control systems using biofungicides in comparison with chemical pesticides.

\section{Materials and Methods}

The object of the study was spring soft wheat of the Yoldyz variety. The standard chemical fungicides were Lamador ${ }^{\circledR}$ for seed treatment and Falcon ${ }^{\circledR}$ for plant spraying. Biofungicides Baxis ${ }^{\circledR}$ (Bacillus subtilis strain 63-Z) and Pseudobacterin 2® (Pseudomonas aureofaciens strain BS 1393) were used in the experiment.

The studies were carried out in 2018-2020 on the experimental fields, which were located in LLC "Agrofirma Igenche" of the Arsk municipal district of the Republic of Tatarstan. The weather conditions varied during the years of the study. In 2018 and 2019, they were periodically dry and in 2020 they were favorable for the development of spring wheat and the formation of its harvest. The soil of the experimental plots was highly cultivated grey wood and medium loamy.

The experiment scheme:

1. Control without the use of plant protection products;

2. Seed treatment (ST) Lamador, $0.21 / \mathrm{t}$;

3. Plant spraying (PS) Falcon, 0.61 / ha;

4. Lamador (ST) + Falcon (PS);

5. Baxis, 1.0 1/t (ST);
6. Pseudobacterin 2, 1.0 1/t (ST);

7. Pseudobacterin 2, 1.0 1/ha (PS);

8. Baxis (ST) + Pseudobacterin 2 (PS);

9. Pseudobacterin 2 (ST) + Pseudobacterin 2 (PS);

Seed treatment was carried out with a liquid flow rate of 10 1/ha and spraying with a flow rate of $200 \mathrm{l} / \mathrm{ha}$. Spraying was carried out during the earing phase of wheat. The experiment was repeated four times. Diseases were recorded according to standard methods. Statistical data processing was carried out using Student's t-test $(\mathrm{P}<0.05)$.

\section{Results and discussion}

The use of various plant protection schemes affected the biometric indicators of wheat plants (Table 1).

The results of the assessment showed that the use of fungicides had an effect on the length of the stem. It is necessary to note that in the options where only spraying of plants with both a chemical and a biological fungicide was carried out, there were no significant differences in the length of the stem in comparison with the control one. When processing only seeds, the stimulation of stem growth was observed, while there were no significant differences in the length of the stem when using the chemical Lamador and biological agents (Baxis and Pseudobacterin 2). Similar results were observed during the use of schemes with seed treatment and subsequent plant spraying.

Table 1. Biometric indicators of spring wheat plants of the Yoldyz variety (full ripeness), 2018-2020

\begin{tabular}{|c|c|c|c|c|}
\hline Option & Stem length, cm & Ear length, cm & $\begin{array}{c}\text { Number of grains in an } \\
\text { ear, pcs. }\end{array}$ & $\begin{array}{c}\text { Weight of } \\
1000 \text { grains, g }\end{array}$ \\
\hline Control & 79.0 & 8.1 & 32.6 & 40.4 \\
\hline Lamador (ST) & 87.6 & $8.1 *$ & 35.4 & $38.9 *$ \\
\hline Falcon (PS) & $82.8 *$ & $7.8 *$ & $31.5^{*}$ & $38.8 *$ \\
\hline Lamador $(\mathrm{ST})+$ Falcon$(\mathrm{PS})$ & 85.9 & $8.5^{*}$ & 35.9 & $37.9 *$ \\
\hline Baxis (ST) & 87.3 & $8.4 *$ & 36.0 & $39.9 *$ \\
\hline Pseudobacterin 2 (ST) & 84.2 & $8.5^{*}$ & 37.6 & $39.2 *$ \\
\hline Pseudobacterin 2 (PS) & $82.6 *$ & $7.9 *$ & $31.7 *$ & $40.0 *$ \\
\hline Baxis (ST) + Pseudobacterin 2 (PS) & 88.0 & 8.7 & 38.0 & $38.8 *$ \\
\hline $\begin{array}{c}\text { Pseudobacterin } 2(\mathrm{ST})+ \\
\text { Pseudobacterin } 2(\mathrm{PS})\end{array}$ & 88.0 & $8.2 *$ & 34.7 & $40.9 *$ \\
\hline
\end{tabular}

Legend: 1 . ST - seed treatment, PS - plant spraying; $2{ }^{*}$ - the difference is insignificant in relation to the control at $\mathrm{P}=0,05$.

In all options with chemical and biological fungicides, no significant changes in the ear length were observed in comparison with the control. Except for the options with plant spraying only, in all other options with chemical and biological fungicides, the increase in the number of grains in one ear was noted. The largest number of grains in one ear was during the use of the Baxis (ST) + Pseudobacterin 2 (PS) scheme. The use of fungicides did not have a pronounced effect on the weight of 1000 wheat grains in comparison with the indicators in the control group.

One of the purposes of the use of fungicides is to protect plants from diseases. The results of the record of the development of diseases are presented in Table 2.

The development of root rot in the experiments was at a low level, which was associated with a high level of agricultural technology in the cultivation of spring wheat in the experimental fields and a low level of infection in the soil and seeds. The minimum damage to spring wheat plants by root rot was in the options where the biofungicide Baxis (Bacillus subtilis strain 63-Z) was used for seed treatment, while the effectiveness of this agent was superior to that of a standard chemical fungicide.

For leaf septoria, the chemical fungicide Falcon, either alone or in combination with seed treatment with Lamador, had the strongest effect on the reduction of plant damage. However, good results were also obtained when using the biofungicide Pseudobacterin 2, both for spraying and in conjunction with seed treatment. Similar results were obtained for powdery mildew. The use of chemicals better controlled this disease, but in the option with biofungicides - Pseudobacterin 2 (ST) + 
Pseudobacterin 2 (PS), the indicators were close to the values for standard fungicides.

One of the most urgent problems in the production of spring wheat for seed purposes is the black contamination of the seeds of new crops. After harvesting, the prevalence of this disease was determined (Table 3).

Table 2. Development of diseases of spring wheat variety Yoldyz in the flowering phase, \%, 2018-2020

\begin{tabular}{|c|c|c|c|}
\hline Option & Root rot & $\begin{array}{c}\text { Leaf } \\
\text { septoria }\end{array}$ & $\begin{array}{c}\text { Powdery } \\
\text { mildew }\end{array}$ \\
\hline Control & 1.2 & 6.9 & 13.8 \\
\hline Lamador (ST) & 0.2 & 2.1 & 3.9 \\
\hline Falcon (PS) & 1.1 & 0.1 & 1.0 \\
\hline Lamador (ST) + Falcon (PS) & 0.4 & 0.3 & 0.8 \\
\hline Baxis (ST) & 0.1 & 2.4 & 1.4 \\
\hline Pseudobacterin 2 (ST) & 0.3 & 1.0 & 11.8 \\
\hline Pseudobacterin 2 (PS) & 0.2 & 7.9 & 1.9 \\
\hline Bseudobacterin 2 (ST) + Pseudobacterin 2 (PS) & 0.1 & 2.0 & 3.0 \\
\hline
\end{tabular}

Legend: 1. ST - seed treatment, PS - plant spraying.

Table 3. Black contamination of seeds of a new crop with in spring wheat Yoldyz, \%, 2018-2020

\begin{tabular}{|c|c|c|}
\hline Option & $\begin{array}{c}\text { Contamination, } \\
\mathbf{\%}\end{array}$ & $\begin{array}{c}\text { Deviation from } \\
\text { control, } \mathbf{\pm \%}\end{array}$ \\
\hline Control & 24.3 & \\
\hline Lamador (ST) & 16.5 & -7.8 \\
\hline Falcon (PS) & 1.4 & -22.9 \\
\hline Lamador (ST) + Falcon (PS) & 3.2 & -21.1 \\
\hline Baxis (ST) & 17.0 & -7.3 \\
\hline Pseudobacterin 2 (ST) & 21.2 & -3.1 \\
\hline Pseudobacterin 2 (PS) & 2.1 & -22.2 \\
\hline Baxis (ST) + Pseudobacterin 2 (PS) & 3.0 & -21.3 \\
\hline Pseudobacterin 2 (ST) + Pseudobacterin 2 (PS) & 2.5 & -21.8 \\
\hline
\end{tabular}

Legend: 1 . ST - seed treatment, PS - plant spraying

The results of assesment showed that the seeds in the control were heavily contaminated with black infection. Seed treatment with both a chemical fungicide and biological preparations had a weak effect on the reduction of the infection with this disease. Spraying plants with fungicides significantly (9-10 times) reduced the prevalence of black contamination. Among the studied agents the strongest effect was observed when using the biofungicide Pseudobacterin 2, which surpassed the standard chemical fungicide in its effect.

Table 4. Productivity of spring wheat variety Yoldyz when using various fungicides, t/ha, 2018-2020

\begin{tabular}{|c|c|c|c|c|}
\hline \multirow[t]{2}{*}{ Option } & \multicolumn{3}{|c|}{ Research year } & \multirow{2}{*}{\begin{tabular}{|c|} 
Average \\
over 3 years
\end{tabular}} \\
\hline & 2018 & 2019 & 2020 & \\
\hline Control & 4.50 & 4.08 & 4.47 & 4.35 \\
\hline Lamador (ST) & 4.71 & $4.12 *$ & 4.81 & 4.55 \\
\hline Falcon (PS) & 4.73 & 4.26 & 5.69 & 4.89 \\
\hline Lamador (ST) + Falcon (PS) & 4.79 & 4.41 & 6.27 & 5.16 \\
\hline Baxis (ST) & 4.74 & 4.21 & 5.00 & 4.65 \\
\hline Pseudobacterin $2(\mathrm{ST})$ & $4.68^{*}$ & $4.16^{*}$ & 5.27 & 4.70 \\
\hline Pseudobacterin 2 (PS) & $4.62 *$ & $4.05 *$ & 5.61 & 4.76 \\
\hline Baxis (ST) + Pseudobacterin $2(\mathrm{PS})$ & $4.64 *$ & 4.96 & 6.76 & 5.45 \\
\hline Pseudobacterin $2(\mathrm{ST})+$ Pseudobacterin $2(\mathrm{PS})$ & 4.70 & 4.52 & 6.34 & 5.19 \\
\hline $\operatorname{LSD}_{05}$ & 0.17 & 0.19 & 0.24 & \\
\hline
\end{tabular}

Legend: 1 . ST - seed treatment, PS - plant spraying; $2{ }^{*}$ - the difference is insignificant in relation to the control at $\mathrm{P}=0,05$

During the analysis of the yield, it is necessary to note that the effect of the studied agents strongly depended on weather conditions. In arid 2018 and 2019, the benefits of both chemical and biological fungicides were significantly lower than in the more humidified 2020. This was also explained by the fact that if in 2018-2019, the development of diseases was at a low level and then in 2020 the conditions were favorable.

In arid conditions, the use of Pseudobacterin 2 for both seed treatment and spraying did not give a significant increase in yield compared to the control one, but under the conditions of 2020, the increase in yield during the use of this biofungicide was significant.

In arid conditions, there was practically no difference during the use of only seed treatment and only spraying with both chemical and biological fungicides. However, in a humid year 2020, the use of plant spraying gave a greater yield increase than just seed treatment. Thus, plant spraying with Falcon provided the increase in the yield in comparison with seed treatment by $0.34 \mathrm{t} / \mathrm{ha}$, 
and plant spraying with Pseudobacterin 2 increased yield by $0.34-0.61 \mathrm{t} / \mathrm{ha}$ in comparison with options where only seeds were treated with biofungicides.

In all the research years, the combined use of fungicides (both chemical and biological) for seed treatment and subsequent plant spraying had a stronger effect than their use separately. This effect was especially strong in a well-humid 2020.

In average, over 3 years of research, the highest yield of spring soft wheat was obtained using the treatment scheme - Baxis (ST) + Pseudobacterin 2 (PS). This scheme provided the increase in the yield by $1.1 \mathrm{t} / \mathrm{ha}$ compared to control and by 0.29 t/ha when using standard chemical fungicides for seed treatment and spraying. Taking into account the fact that the processing costs during the use of biofungicides were 3.5 times less than chemical preparations, the economic efficiency of the use of this scheme was high.

\section{Conclusion}

The studies were aimed to assess the possibility of the use of biofungicides in systems for the protection of spring wheat from diseases in the conditions of the Republic of Tatarstan in comparison with standard chemical agents.

It was found that seed treatment with chemical and biological fungicides stimulates the growth of the wheat stem. The application of seed treatment and spraying increases the number of grains in the ear.

The minimum damage to spring wheat plants by root rot was in the options where the biofungicide Baxis was used for seed treatment, while this agent was more effective than the indicators of a standard chemical fungicide. In case of leaf septoria and powdery mildew, chemical fungicides showed the best results. However, in case of powdery mildew, the difference between the use of chemical and biological fungicides for plant treatment was insignificant.

The effect of fungicide treatments was directly determined by weather conditions during the years of research. If under the periodically dry conditions the return on their use was lower, then under favorable humid conditions, the effect of their use was more significant. The use of Pseudobacterin 2 (Pseudomonas aureofaciens strain BS 1393) under arid conditions does not have a positive effect on yield growth, which once again confirms the opinion that the effectiveness of the use of biological products strongly depends on environmental conditions [27].

The maximum yield over the years of research was obtained using the following scheme: seed treatment with Baxis (Bacillus subtilis strain 63-Z) + plant spraying with Pseudobacterin 2 (Pseudomonas aureofaciens strain BS 1393). The use of such a scheme significantly reduced the cost of the protection of wheat plants from diseases.

As a result of this research, it was shown that with a weak and medium development of diseases, the use of biofungicides could be an effective alternative to the use of standard chemical fungicides.

\section{Recommendations}

During weak and medium development of diseases on wheat of the Yoldyz variety we recommend using the protection scheme - seed treatment with Baxis (Bacillus subtilis strain 63-Z) + plant spraying with Pseudobacterin 2 (Pseudomonas aureofaciens strain BS 1393).

\section{References}

1. J. Hellin, B. Shiferaw, J.E. Cairns, M. Reynolds, I. Ortiz-Monasterio, M. Banziger et al., J. Dev. Agric. Econ., 4 (2012)

2. A. Enghiad, D. Ufer, A.M. Countryman, D.D. Thilmany, Int. J. of Agron., 2017 (2017)

3. U. Grote, A. Fasse, T.T. Nguyen et al., Front. Sustain. Food Syst., 4, 617009 (2021)

4. M. Amirov, F. Shaikhutdinov, I. Serzhanov, A. Serzhanova, BIO Web Conf., 17, 00071 (2020)

5. M. Amirov, I. Serzhanov, F. Shaikhutdinov, A. Serzhanova, K. Partoev, BIO Web Conf., 27, 00075 (2020)

6. E. Duveiller, R.P. Singh, J.M. Nicol, Euphytica, 157 (2007)

7. M. Figueroa, K.E. Hammond-Kosack, P.S. Solomon, Mol. Plant Path., 19 (2018)

8. R. Dean, J.A.L. Van kan, Z.A. Pretorius, K.E. Hammond-Kosack, A. Di Pietro, P.D. Spanu, J.J. Rudd, M. Dickman et al., Mol. Plant Path., 13 (2012)

9. A.O. Sagitov, Central Asia Region Integrated Pest Management Stakeholders Forum (27-29 May, 2007)

10. D.A. Landis, N. Saidov, A. Jaliov, M. El Bouhssini, M. Kennelly, C. Bahlai, J.N. Landis, K. Maredia, J. of Integ. pest manag., 7, 1 (2016)

11. E. Kirby, T. Paulitz, T. Murray, K. Schroeder, X. Chen, Washington State University Extension Publication EM 108-08 (2017)

12. J.B. Matanguihan, K.M. Murphy, S.S. Jones, Plant Disease, 95, 2 (2011)

13. M. Carmona, F. Sautua, O. Pérez-Hérnandez, E.M. Reis, Front. Plant Sci., 11, 733 (2020)

14. E.M. Reis, M.A. Carmona (Nova Science Publ., New York, 2013)

15. T.M. Wieczorek, L.N. Jørgensen, H.-B. Christiansen, B.B. Olsen, Appl. Crop Protect., 74 (2016)

16. P. Cheval, A. Siah, M. Bomble, A.D. Popper, P. Reignault, P. Halama, Crop Protect., 92 (2017)

17. A.V. Bruggen, A. Gamliel, M. Finckh, Pest manag. Sci., 72, 1 (2016)

18. V. Pavlyushin, BIO Web of Conferences, 18, 00024 (2020)

19. G.E. Heimpel, N. Mills (Cambridge University Press, 2017) 
20. U. Conrath, G.J.M. Beckers, C.J.G. Langenbach, M.R. Jaskiewicz, Annu. Rev. Phytopathol., 53 (2015)

21. K. Jürgen, K. Rogier, R. Willem, J. Front. in Plant Sci., 10 (2019)

22. T. Glare, J. Caradus, W. Gelernter, T. Jackson, N. Keyhani, J. Köhl et al., Trends Biotechnol., 30 (2012).

23. D. Zafari, M.M. Koushki, E. Bazgir, Afr. J. Biotechnol., 7, 20 (2008)
24. A. Mehrdad, V. Yalda, S. Naser, Open Agricult., 5, $1(2020)$

25. J.A. Abbey, D. Percival, L. Abbey, S.1.K. Asiedu, B. Prithiviraj, A. Schilder, Biocontrol Sci. and Technol. (2018)

26. A. Nega, J. of Biol., Agricult. and Health., 4, 27 (2014)

27. M. Bardin, S. Ajouz, M. Comby, M. Lopez-Ferber, B. Graillot, M. Siegwart, P.C. Nicot, Front. Plant Sci., 6 (2015) 